\title{
Estudo cefalométrico das alturas faciais anterior e posterior, em jovens brasileiros melanodermas, com "oclusão normal"
}

Lívia Maria Andrade de Freitas Uchiyama*, Arnaldo Pinzan**, Célia Regina Maio Pinzan-Vercelino***, Guilherme Janson ${ }^{\star \star \star \star}$, Marcos Roberto de Freitas ${ }^{\star \star \star \star \star}$

\section{Resumo}

Objetivo: com o propósito de apresentar um padrão cefalométrico específico para os jovens brasileiros melanodermas, este estudo se propôs a obter os valores médios de normalidade para algumas das grandezas cefalométricas esqueléticas, no sentido vertical da face (alturas faciais anterior e posterior) e verificar a presença de dimorfismo entre os gêneros. Metodologia: a amostra constituiu-se de 56 telerradiografias, em norma lateral, sendo 28 do gênero masculino, com idade média de 13,93 anos (idade mínima de 12,08 anos e máxima de 15,75 anos) e 28 do gênero feminino, com idade média de 13,79 anos (idade mínima de 12,58 anos e máxima de 15,67 anos), obtidas de amostras de jovens brasileiros, melanodermas, não submetidos a tratamento ortodôntico e que apresentavam "oclusão normal", pertencentes ao arquivo da Disciplina de Ortodontia da Faculdade de Odontologia de Bauru - Universidade de São Paulo. As medidas cefalométricas empregadas foram de acordo com as Análises de Wylie, Johnson, Siriwat, Jarabak, Gebeck, Merrifield e Horn. Os valores foram submetidos à análise estatística pelo teste $t$ independente para comparar as variáveis entre os gêneros. Resultados: com base nos resultados obtidos neste estudo, verificou-se que os jovens brasileiros melanodermas apresentaram valores médios específicos para as grandezas cefalométricas esqueléticas, no sentido vertical da face. Pôde-se observar a presença de dimorfismo, com os valores das grandezas das alturas faciais anterior e posterior total e superior (AFAT; AFAS; AFPT; AFPS) e as proporções faciais superior e inferior, com a altura posterior total (AFPS/AFPT; AFPI/AFPT), apresentando um maior desenvolvimento vertical anterior da face no gênero masculino. Uma maior proporção AFPS/AFPT foi encontrada para o gênero masculino e o gênero feminino apresentou valor superior de AFPI. Conclusão: as normas cefalométricas guiam o clínico para o respeito com a morfologia e o padrão facial, considerando fatores existentes como a miscigenação racial e sua origem geográfica.

Palavras-chave: Grupos étnicos. Dimensão vertical. Cefalometria.

* Mestre e Doutoranda em Ortodontia pela Faculdade de Odontologia de Bauru, Universidade de São Paulo.

** Professor associado do Departamento de Odontopediatria, Ortodontia e Saúde Coletiva da Faculdade de Odontologia de Bauru, da

Universidade de São Paulo.
*** Mestre e Doutora em Ortodontia pela Faculdade de Odontologia de Bauru, Universidade de São Paulo.

${ }_{\star \star \star \star \star}^{\star \star *}$ Professor Titular do Departamento de Odontopediatria, Ortodontia e Saúde Coletiva da Faculdade de Odontologia de Bauru, da Universidade de São Paulo.

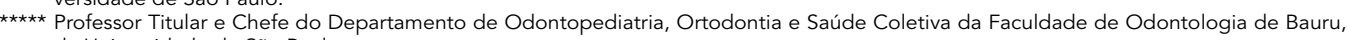
da Universidade de São Paulo. 


\section{INTRODUÇÃO}

Atualmente, as áreas metropolitanas do mundo têm uma população muito mais diversa, trazendo a necessidade de reconhecer que um único padrão de estética facial pode não ser apropriado para as decisões de diagnóstico e plano de tratamento para indivíduos de vários passados étnicos, que migraram para distintas regiões geográficas ${ }^{33}$.

A importância em estudar os componentes verticais da face e relacioná-los com as características normais e individuais em diversos grupos étnicos, com diferentes influências culturais e sociais, está fundamentada no questionamento das limitações do tratamento ortodôntico e suas implicações clínicas, utilizando mecânicas que comprometam a estética facial e as metas terapêuticas. Os valores normativos das grandezas cefalométricas, para diferentes grupos étnicos, devem ser interpretados para complementarem o diagnóstico e plano de tratamento, de acordo com as necessidades e expectativas individuais do paciente ${ }^{2,22}$. A literatura ressalta a carência de estudos cefalométricos, referente às diferenças e comparações da morfologia facial entre esses indivíduos de diferentes gru$\operatorname{pos}^{2,3,14,15,25,27,33}$

Richardson ${ }^{39}$ questionou se realmente existiam diferenças étnicas nas características faciais. A dúvida seria quanto à sua magnitude. Estas diferenças estariam relacionadas, com maior intensidade, a fatores geográficos e ecológicos.

Inúmeros estudos ${ }^{10,19,41,45,47,49}$ se limitaram a indivíduos leucodermas, para descrever as características esqueléticas e dentárias da mordida aberta anterior, assim como das discrepâncias esqueléticas verticais. Entretanto, Beane et al. ${ }^{7}$ relataram resultados de estudos onde a prevalência e a severidade da mordida aberta anterior foram associadas com a etnia. Significativamente, a incidência foi maior em crianças melanodermas $(16,3 \%)$ comparada a crianças leucodermas (4\%), indicando que a população de melanodermas pode, às vezes, apresentar uma incidência até quatro vezes maior de mordida aberta que a leucoderma. Porém, são escassos os trabalhos na literatura ${ }^{40}$ que explicam os motivos desta maior incidência em indivíduos melanodermas ${ }^{7}$.

Portanto, buscando maior conhecimento neste assunto, este trabalho teve a finalidade de propor um padrão cefalométrico específico para os jovens brasileiros melanodermas, no sentido vertical da face.

\section{PROPOSIÇÃO}

Com o propósito de apresentar um padrão cefalométrico específico das alturas faciais anterior e posterior, para os jovens brasileiros melanodermas, utilizando medidas no sentido vertical da face, este estudo objetivou:

- Obter os valores médios de normalidade para as grandezas cefalométricas esqueléticas de jovens brasileiros melanodermas.

- Identificar a presença ou ausência de dimorfismo entre os gêneros.

\section{MATERIAL E MÉTODOS \\ Material}

O material utilizado constituiu-se de 56 telerradiografias cefalométricas, em norma lateral, referentes a uma amostra de brasileiros melanodermas com oclusão normal, pertencentes ao arquivo da Disciplina de Ortodontia - Faculdade de Odontologia de Bauru da Universidade de São Paulo.

Os critérios utilizados para a seleção da amostra foram a presença dos dentes permanentes em oclusão, exceto os terceiros molares, relações normais de molares, pequeno ou nenhum grau de apinhamento, ausência de mordida cruzada, trespasses vertical e horizontal normais, um perfil agradável e nunca submetidos a tratamento ortodôntico.

A amostra de oclusão normal de brasileiros melanodermas, com filiação racial dos povos bantos, foi composta por 56 jovens, sendo 28 do gênero masculino e 28 do gênero feminino, com idade média de 13,86 anos (idade mínima de 12,08 anos e máxima de 15,75 anos). 


\section{Métodos}

\section{Elaboração do cefalograma}

Após a execução do desenho anatômico, os pontos foram identificados e, posteriormente, digitalizados por intermédio de uma mesa digitalizadora Numonics A-30TL.F (Numonics Corporation, Montgomeryville, PA, EUA), conectada a um microcomputador com processador AMD K-6 II $500 \mathrm{MHz}$, para obtenção das grandezas cefalométricas. Os traçados e a digitalização dos pontos foram realizados pelo examinador, utilizando-se o padrão Ortho Lateral do programa Dentofacial Planner 7.02 (Dentofacial Planner Software Inc., Toronto, Ontário, Canadá) para a realização das medições. Foi efetuada a correção do fator de magnificação (6\%), realizada pelo próprio programa.

\section{Delimitação das estruturas anatômicas}

O desenho anatômico está de acordo com o preconizado por Krogman, Sassouni ${ }^{29}$; Interlandi ${ }^{26}$ e Vion ${ }^{48}$, com as seguintes estruturas anatômicas (Fig. 1): sela túrcica; clívus; cortical externa do osso frontal e ossos nasais; média da fissura pterigomaxilar; média das bordas inferiores das órbitas; média dos meatos acústicos externos; maxila; mandíbula; dentes (Incisivos centrais e primeiros molares superiores e inferiores) e perfil tegumentar.

\section{Demarcação dos pontos e traçado de} orientação: linhas e planos

Após a confecção do desenho anatômico, localizaram-se os pontos cefalométricos, de acordo com Krogman, Sassouni ${ }^{29}$ e Miyashita ${ }^{34}$ : S (Sela); N (Násio); ENA (Espinha nasal anterior); ENP (Espinha nasal posterior); Me (Mentoniano); Go (Gônio) e Ar (Articular) (Fig. 1).

Localizados os pontos cefalométricos, traçaram-se os planos, as linhas e foram demarcados os pontos construídos, Ar' e ENA', de acordo com Wylie, Johnson ${ }^{51}$; Siriwat, Jarabak ${ }^{44}$ e Horn ${ }^{23}$.

1) Linha N - Me: linha formada pela união dos pontos Násio (N) e Mentoniano (Me);
2) Linha ENA perp.: linha formada pela projeção do ponto Espinha nasal anterior (ENA) e perpendicular à linha $\mathrm{N}$ - Me;

3) Plano Palatino (PP): linha que une as Espinhas nasais anterior (ENA) e posterior (ENP);

4) Linha PP - Me: linha perpendicular ao Plano Palatino (PP) que une este plano ao ponto Mentoniano (Me);

5) Plano Mandibular (PM): representado pela linha que passa pelo ponto Mentoniano (Me) e tangente ao bordo posterior da base da mandíbula;

6) Linha Ar - PM: linha que une o ponto Articular (Ar) ao Plano Mandibular (PM), tangenciando o bordo posterior do ramo da mandíbula;

7) Linha S - Go: linha formada pela união dos pontos Sela (S) e Gônio (Go);

8) Linha Ar perp.: linha formada pela projeção do ponto Articular (Ar) e perpendicular à linha $\mathrm{S}$ - Go;

9) Ponto ENA' (projeção do ponto ENA): ponto formado pela intersecção da linha ENA perp. com a linha N-Me;

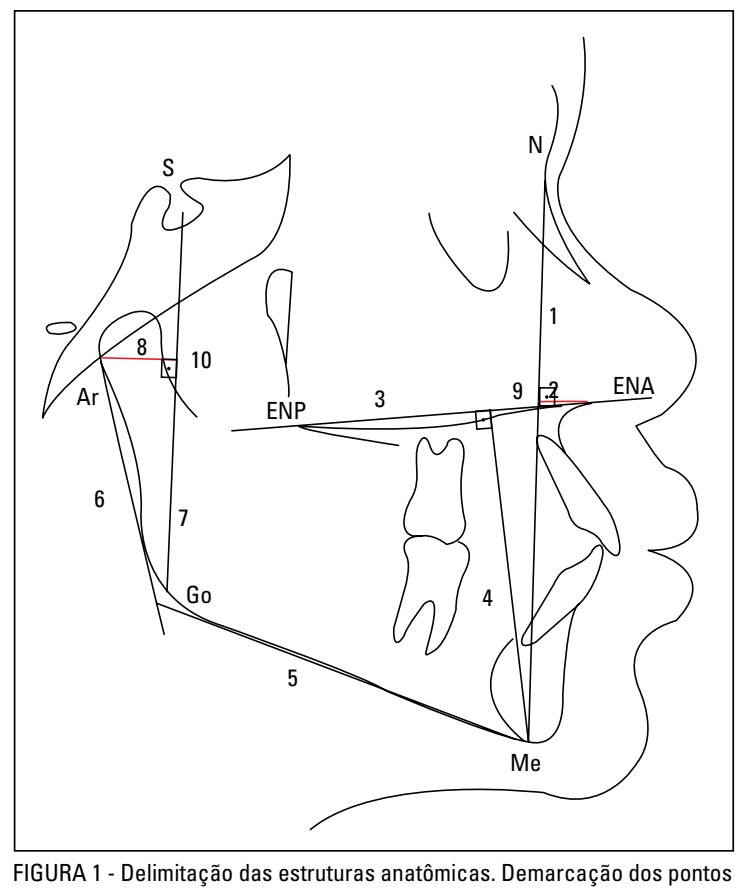
e traçados de orientação: linhas e planos. 
10) Ponto Ar' (projeção do ponto Ar): ponto formado pela intersecção da linha Ar perp com a linha S-Go.

Medidas cefalométricas no sentido vertical da face

Medidas empregadas de acordo com a Análise de Wylie e Johnson ${ }^{51}$ (Fig. 2):

- Altura Facial Anterior Total (AFAT): distância linear do ponto Násio (N) ao ponto Mentoniano (Me);

- Altura Facial Anterior Superior (AFAS): distância linear, mensurada sobre a linha N-Me, do ponto Násio (N) ao ponto ENA';

- Altura Facial Anterior Inferior (AFAI): distância linear, mensurada sobre a linha N-Me, do ponto ENA' ao ponto Mentoniano (Me);

- Proporção entre a Altura Facial Anterior Superior e a Altura Facial Anterior Total (AFAS/ AFAT): razão entre as medidas Altura Facial Anterior Superior (AFAS) e a Altura Facial Anterior Total (AFAT);

- Proporção entre a Altura Facial Anterior Inferior e a Altura Facial Anterior Total (AFAI/ AFAT): razão entre as medidas Altura Facial Anterior Inferior (AFAI) e a Altura Facial Anterior Total (AFAT).

Medidas empregadas de acordo com a Análise de Siriwat e Jarabak ${ }^{44}$ (Fig. 2):

- Altura Facial Posterior Total (AFPT): distância linear do ponto Sela (S) ao ponto Gônio (Go);

- Altura Facial Posterior Superior (AFPS): distância linear, mensurada sobre a linha S-Go, do ponto Sela (S) ao ponto Ar';

- Altura Facial Posterior Inferior (AFPI): distância linear, mensurada sobre a linha S-Go, do ponto Ar' ao ponto Gônio (Go);

- Proporção entre a Altura Facial Posterior Superior e a Altura Facial Posterior Total (AFPS/ AFPT): razão entre as medidas Altura Facial Posterior Superior (AFPS) e a Altura Facial Posterior Total (AFPT);
- Proporção entre a Altura Facial Posterior Inferior e a Altura Facial Posterior Total (AFPI/ AFPT): razão entre as medidas Altura Facial Posterior Inferior (AFPI) e a Altura Facial Posterior Total (AFPT).

Medidas empregadas de acordo com a Análise de Gebeck e Merrifield ${ }^{21,32}$ (Fig. 2):

- Altura Facial Anterior (AFA): distância linear do Plano Palatino (PP) perpendicular ao ponto Mentoniano (Me);

- Altura Facial Posterior (AFP): distância linear do ponto Articular (Ar) ao Plano Mandibular (PM);

- Índice da Altura Facial de acordo com Horn ${ }^{23}$ : $[\mathrm{IAF}=(\mathrm{AFP} / \mathrm{AFA}) \times 100]$

\section{Análise estatística}

Erro do método

Para a determinação da confiabilidade dos resultados, vinte radiografias selecionadas ao acaso foram novamente traçadas e digitalizadas, pelo mesmo pesquisador, com um intervalo de 10 dias.

Para cada uma das grandezas cefalométricas estudadas, foram avaliados os erros sistemáticos e casuais, independentemente. O erro sistemático foi calculado pelo teste $t$ pareado, conforme preconizado por Houston ${ }^{24}$. A aplicação da fórmula proposta por Dahlberg ${ }^{16}\left(\mathrm{Se}^{2}=\right.$ somatória $\left.\mathrm{d}^{2} / 2 \mathrm{n}\right)$ possibilitou

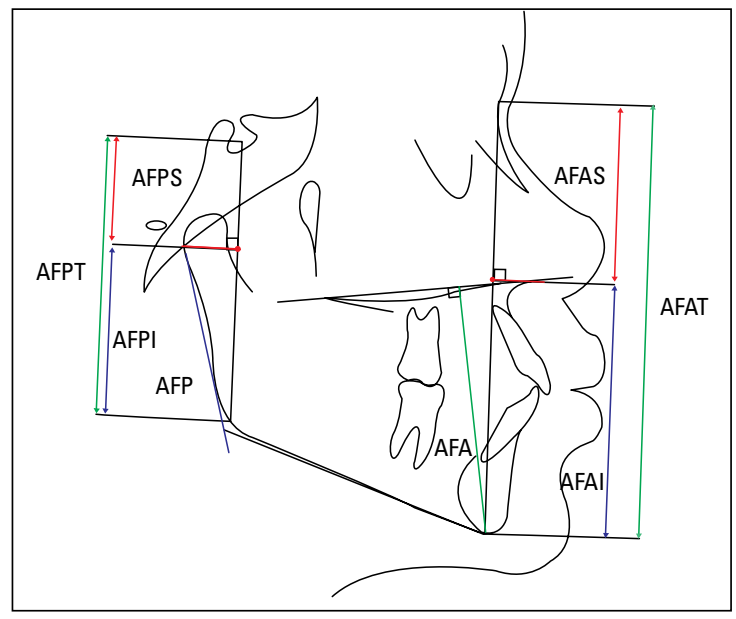

FIGURA 2 - Medidas cefalométricas no sentido vertical da face. 
estimar a resultante dos erros casuais. Consideramse significantes os erros acima de $1 \mathrm{~mm}$ para as medidas lineares e $1,5^{\circ}$ para as angulares ${ }^{16}$.

\section{Análise descritiva e comparativa}

Para a análise estatística dos dados utilizou-se o teste $t$ independente, para comparação dos valores das grandezas cefalométricas. Estes testes foram realizados no programa de computador Statistica for Windows 5.0 (STATISTICA for Windows. StatSoft, Inc. (1995, Tulsa, OK, EUA). Os resultados foram considerados estatisticamente significantes com valor de $\mathrm{p}<0,05$.

\section{RESULTADOS}

Os resultados estão apresentados sob a forma de gráficos (Gráf. 1-13). Os valores dos erros casuais $^{16}$ e sistemáticos ${ }^{24}$ e da avaliação intra-examinador foram aceitáveis. A apresentação dos resultados, com a presença de dimorfismo entre gêneros, na forma de gráficos teve por finalidade facilitar a interpretação, observando os distintos valores apresentados na literatura.

\section{DISCUSSÃO}

A harmonia do complexo craniofacial nos sentidos horizontal, transversal e vertical é responsável por despertar o senso individual de beleza e admiração da face humana.

A dimensão vertical destaca-se como um dos fatores que diferencia as más oclusões com um relacionamento dentário idêntico ${ }^{38}$ sendo, portanto, decisivo na escolha da abordagem terapêutica a ser utilizada. Considerando que o tratamento ortodôntico influencia as características faciais, é de fundamental importância que se discuta e leve em consideração os interesses do paciente quanto ao resultado estético final esperado.

A face do indivíduo melanoderma que se apresenta inicialmente com características próprias e peculiares é escassamente explorada pela literatura, principalmente com relação às dimensões esqueléticas verticais, estimulando propostas de padrões cefalométricos específicos para seu estudo, a fim de auxiliar no diagnóstico, no plano de tratamento e na avaliação dos resultados do tratamento ortodôntico.

\section{Comparação das dimensões verticais em indi- víduos melanodermas de diferentes regiões geográficas}

No Brasil, muito particularmente devido à experiência colonial lusitana, não houve segregação de grupos. A miscigenação entre o colonizador português, o indígena e o negro resultou na formação, desde os primeiros tempos da história, em uma população diversificada, sendo o produto de cruzamento de branco-negro, branco-índio, negroíndio parcela ponderável da população brasileira ${ }^{18}$. Cada um dos três grupos básicos (índio, branco e negro) está longe de representar uma etnia pura. Torna-se importante estudar as características da população brasileira, analisando os aspectos somáticos respectivos.

Em particular, o negro, introduzido como escravo, natural do continente africano, também é morfologicamente heterogêneo. Pela sua procedência geográfica pode-se fazer idéia da filiação racial dos representantes importados do grupo negróide. Tendo em vista o índice cefálico e a estatura, pode-se distinguir, no grupo negróide, as etnias típicas de regiões específicas da África: a nigriciana, paleonegróide, nilótica e khoisan. Os povos bantos selecionados para esta pesquisa, por exemplo, predominam nas regiões da costa e contracosta da África e são derivados da mistura de nigricianos e paleonegróides ${ }^{18}$.

Para comparação dos resultados desta pesquisa com outros resultados, faz-se necessário observar, entre outros, os seguintes fatores: diferença de idade entre as amostras; tamanho das amostras; diferenças com relação à metodologia adotada, como diferenças nas definições dos pontos de reparo e técnicas de medidas.

Baumrind e Frantz ${ }^{6}$ avaliaram que o erro médio de identificação de pontos de reparo pode ser 
de 0,37 a $3,75 \mathrm{~mm}$, dependendo do ponto de reparo em particular ${ }^{11}$ e que o erro pode ser de 0,43 a $0,86 \mathrm{~mm}$ e de $0,62^{\circ}$ a $3,54^{\circ}$ para as medidas lineares e angulares, respectivamente, dependendo da medida.

Outro aspecto importante é o fator de magnificação. Neste estudo, efetuou-se a correção deste fator calculado no valor de 6\%. Diversos estudos não especificaram quanto à realização da correção do fator de magnificação $0^{1,3,5,12,20,36,40}$, dificultando assim uma comparação entre as amostras e os valores obtidos, já que a diferença é significativa entre os valores que não foram devidamente corrigidos.

A amostra desta pesquisa consistiu de indivíduos melanodermas com características faciais agradáveis, dentro de um conceito inevitavelmente subjetivo. Por este motivo foi calculado o valor da medida SN.GoGn, para o conhecimento do padrão de crescimento facial e as características morfológicas da presente amostra.

\section{AFAT}

A altura facial anterior total possui crescimento na infância, na adolescência e na fase adulta. O aumento vertical da face foi verificado até a quarta década de vida, entretanto, com o decorrer do tempo, ocorre uma tendência à diminuição ${ }^{46}$.

Na presente pesquisa, os valores de AFAT (Gráf. 1) encontrados para os melanodermas brasileiros com média de idade 13,8 anos apresentaram diferença estatística significante, para o dimorfismo entre os gêneros e maior desenvolvimento vertical da face anterior para o masculino. Essa diferença entre os gêneros corrobora os relatos da literatu$\mathrm{ra}^{1,5,20,30,36}$, uma vez que a altura facial anterior dos indivíduos do gênero masculino é maior que a do feminino ${ }^{35}$, independentemente da idade.

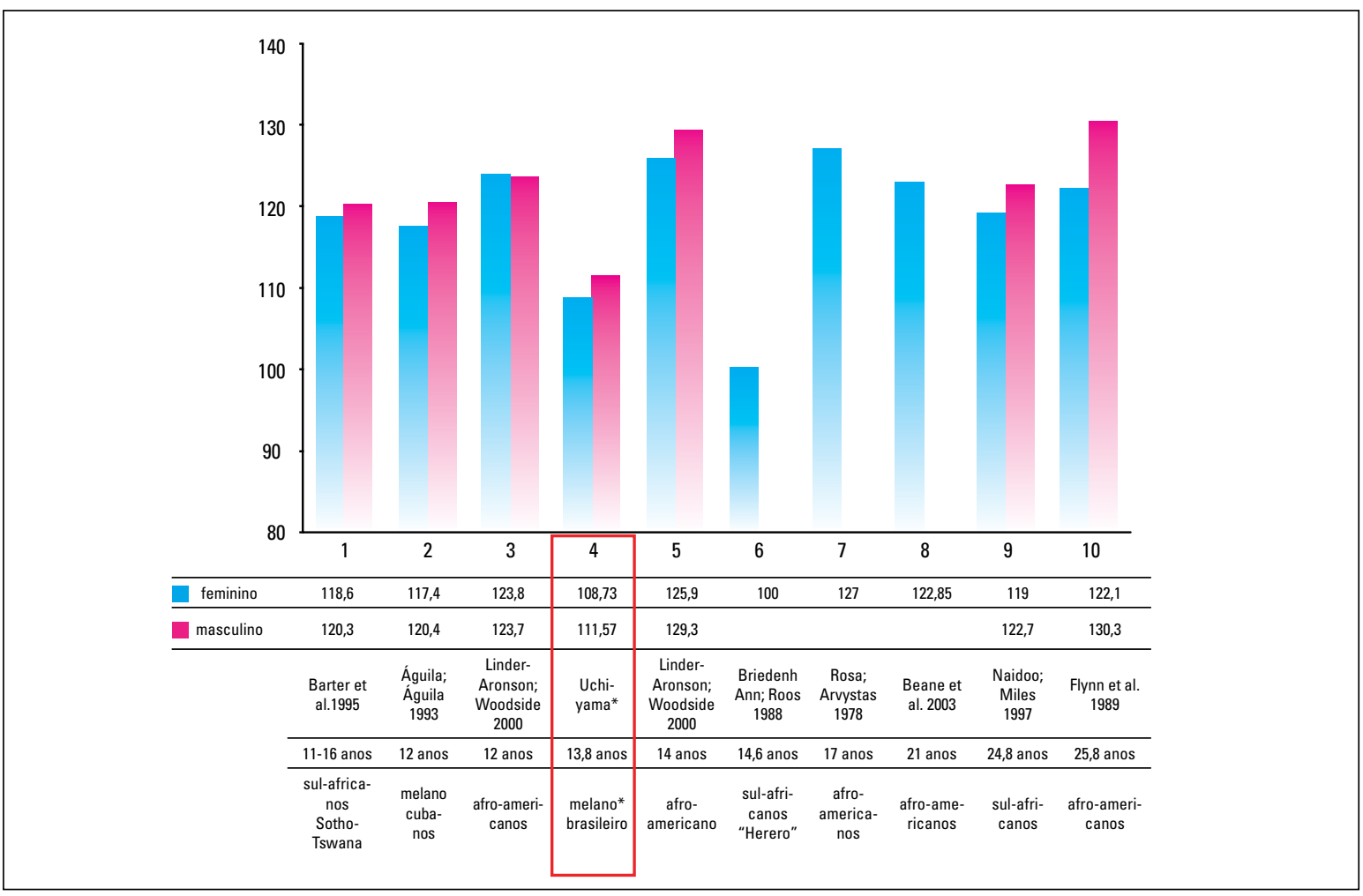

GRÁFICO 3 - Valores de AFAT da amostra de melanodermas: brasileiros $x$ áreas geográficas distintas. *Dimorfismo entre gêneros (pesquisa de UCHIYAMA). 
Os afro-americanos avaliados em estudos comparativos apresentaram AFAT com valores amplamente distintos, sendo maiores quando comparados aos valores da amostra de melanodermas brasileiros $^{7,20,30,40}$.

Os valores aumentados para a AFAT encontrados por alguns autores ${ }^{3,7,20,36,40}$, estudando melanodermas adultos, devem ser atribuídos, em parte, às idades médias das amostras que diferem da idade média da presente amostra $(13,8 a)$ na qual os indivíduos, principalmente do gênero masculino, não expressaram ainda a plenitude de crescimento facial.

Os dados de Linder-Aronson e Woodside ${ }^{30}$ demonstram essa diferença na AFAT, com o passar da idade, já que os valores encontrados nos indivíduos do gênero masculino aos 16 anos foram $5,5 \mathrm{~mm}$ maiores do que os valores encontrados aos 14 anos, considerando ainda que a AFAT possui crescimento também na fase adulta. Além disso, alguns autores ${ }^{1,3,5,12,20,36,40}$ não citam se foram realizados ajustes para as diferenças na magnificação (na presente pesquisa, foi corrigido um aumento de $6 \%$ correspondente à magnificação).

Rosa e $\operatorname{Arvystas}^{40}$ encontraram altos valores para AFAT, avaliando amostra de melanodermas norte-americanos da mesma região geográfica com idade média de 17 anos e 7 meses.

Os valores para AFAT encontrados por Flynn et al..$^{20}$, para uma amostra de melanodermas adultos americanos com idade média de 25,8 anos, foram superiores aos resultados de Naidoo e Miles ${ }^{37}$, para adultos melanodermas sul-africanos da região de Western Cape, sul da África, com idade média de 24,8 anos para o gênero masculino e 23,4 anos para o gênero feminino.

Valores similares aos de Naidoo e Miles ${ }^{37}$ foram encontrados por Barter et al. ${ }^{5}$, no seu estudo com melanodermas de Botswana, pertencentes ao grupo Sotho-Tswana, com idade variando entre 11 e 16 anos.

O único relato da literatura com valores de AFAT inferiores aos da presente pesquisa foi apre- sentado por Briedenhann e Roos ${ }^{12}$, em seu estudo com indivíduos melanodermas africanos com idioma "herero" e idade média de 14,6 anos.

Os valores de Águila, Águila ${ }^{1}$; Linder-Aronson e Woodside ${ }^{30}$ para uma faixa etária idêntica de 12 anos, também apresentaram diferenças, sendo os maiores valores encontrados para os afro-ameri$\operatorname{canos}^{30}$, os quais não indicaram dimorfismo entre os gêneros, e valores menores apresentados pela amostra de melanodermas cubanos ${ }^{1}$, com diferença significante entre os gêneros.

Essa notória variação entre os resultados dos autores supracitados para os melanodermas americanos de diferentes regiões geográficas é reflexo da miscigenação com caucasianos e índios americanos (Mongolóides) ${ }^{17}$.

Comparando-se os resultados dos estudos para melanodermas americanos e sul-africanos, constatou-se a significância nas diferenças cefalométricas entre esses dois grupos ${ }^{12}$.

A diferença entre os resultados do mesmo grupo étnico de diferentes regiões foi descrita por Richardson $^{39}$. A autora observou que há diferenças médias nas características quantificáveis da face de alguns grupos étnicos.

Richardson ${ }^{39}$ afirmou ser surpreendente a semelhança no ângulo facial médio entre os diferentes grupos étnicos na mesma região geográfica. Questionou a existência de diversos grupos étnicos separados por fronteiras culturais climáticas e geográficas que causaram alterações sutis na morfologia facial. Concluiu, assim, que a dificuldade em se definir raça tem como conseqüência a necessidade de acrescentar uma ligação comum aos grupos étnicos como leucodermas suecos, americanos e outros, para que a referência a esses grupos seja feita com mais precisão. Afirmou ainda que as diferenças quantificáveis na região craniofacial somática dos grupos étnicos, que persistem por várias gerações em áreas geográficas iguais ou semelhantes, são pequenas.

Segundo Richardson ${ }^{39}$, os autores que especificaram diferenças morfológicas extremas nos 
vários grupos étnicos poderiam possivelmente ter obtido amostras de um segmento em um extremo da escala do perfil do grupo, ao invés de obter uma amostra que poderia ser considerada a média do grupo. As diferenças também poderiam representar a comparação de dois ou mais grupos de diferentes regiões geográficas, onde as diferenças são principalmente relacionadas a fatores geográficos e não a fatores étnicos.

Dentre a variação por distribuição geográfica de melanodermas nos EUA, outros problemas podem ser identificados na comparação de estudos cefalométricos de melanodermas americanos, tais como o tipo de análise utilizada, idade da amostra, tamanho da amostra, critérios de seleção, métodos estatísticos, definições de normalidade clínica e definições da designação negra ${ }^{20}$.

\section{AFAS}

Bishara ${ }^{8,9}$ observou, em faces normais, maior desenvolvimento da AFAS em jovens de ambos os gêneros, com idades de 4,5 a 10 anos, e menor crescimento em jovens entre 15 e 25,5 anos. Linder-Aronson e Woodside ${ }^{30}$ verificaram que a AFAS em faces equilibradas teve maior crescimento que a AFAI dos 7 aos 11 anos.

Os valores da AFAS (Gráf. 2) da presente pesquisa indicaram dimorfismo entre os gêneros, com maior valor para o gênero masculino. Esta diferença existente está de acordo com os resultados encontrados por Linder-Aronson, Woodside ${ }^{30}$; Flynn ${ }^{20} ;$ Naidoo, Miles ${ }^{36}$; Águila, Águila ${ }^{1}$; Bailey e Taylor $^{4}$ e é contrária aos relatos de Barter ${ }^{5}$.

O grupo africano de idioma "herero"12 apresentou o menor valor para AFAS, seguido, em ordem crescente, pela amostra melanoderma brasileira, cujos valores foram inferiores aos valores dos bantus africanos, afro-americanos de outros estudos $4,7,20,30,40$, melanodermas cubanos ${ }^{1}$, sul-afri$\operatorname{canos}^{36}$ e pertencentes ao grupo Sotho-tswana ${ }^{5}$.

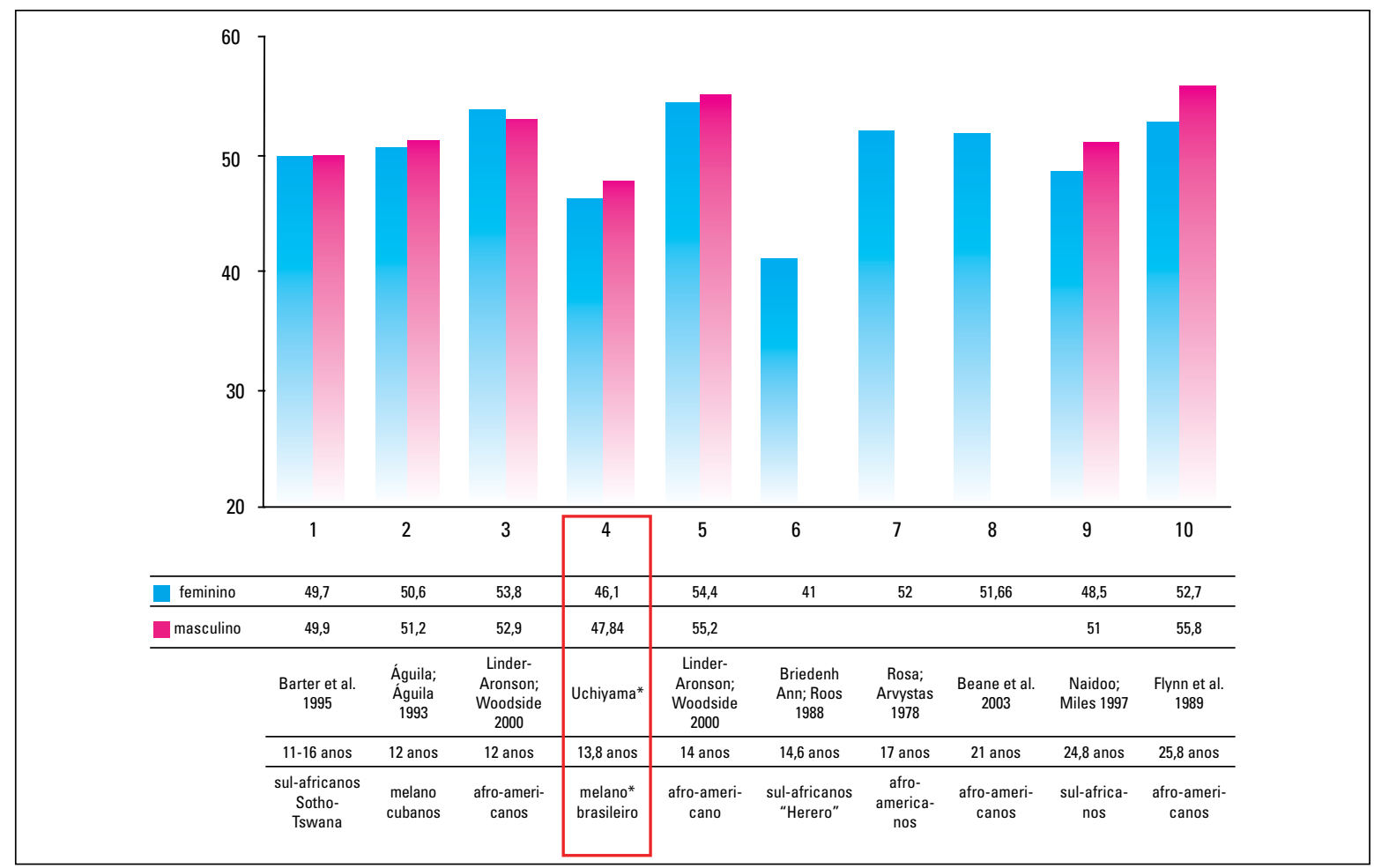

GRÁFICO 2 - Valores de AFAS da amostra de melanodermas: brasileiros $\mathrm{x}$ áreas geográficas distintas.

*Dimorfismo entre gêneros (pesquisa de UCHIYAMA). 


\section{AFAl}

A literatura é unânime em ressaltar maior contribuição da AFAI em relação à AFAS na altura facial total de indivíduos melanodermas de diferentes regiões geográficas ${ }^{1,3,5,7,12,20,30,36,40}$.

É também importante considerar a influência das variações ambientais na AFAI e sua relação com a obstrução nasal, apresentando-se aumentado em indivíduos com deficiência respiratória ${ }^{49}$. Os resultados encontrados neste trabalho para os valores de AFAI (Gráf. 3) não indicaram dimorfismo entre os gêneros, confirmando os resultados de Naidoo, Miles ${ }^{36}$ e Barter et al. ${ }^{5}$, divergindo, entretanto, com Linder-Aronson, Woodside ${ }^{30}$; Flynn ${ }^{20}$; Águila e Águila ${ }^{1}$, que encontraram dimorfismo entre gêneros.

Os valores de AFAI apresentados pelos indivíduos melanodermas brasileiros foram menores quando comparados aos afro-americanos estudados por Beane et al. ${ }^{12}$; Linder-Aronson, Woodside ${ }^{49}$ e Flynn ${ }^{20}$, aos africanos ${ }^{5,36}$ e aos bantus africanos ${ }^{3}$.
Os valores encontrados por Águila e Águila ${ }^{2}$ para melanodermas cubanos foram os que mais se aproximaram dos valores da presente pesquisa, os quais foram superiores ao valor apresentado por Briedenhann e Roos ${ }^{12}$. Já os resultados de Bacon ${ }^{3}$, para os bantus africanos, foram os maiores, para esta grandeza. Estas diferenças devem estar relacionadas à diversidade das faixas etárias das amostras, como também ao grupo étnico e sua origem. As características raciais necessitam uma notória significância quanto à morfologia individual destas amostras, quando selecionadas. Diferencia-se o valor da medida entre indivíduos braquifacial, mesofacial e dolicofacial.

\section{AFPT (AFPS e AFPI) (Gráf. 4, 5, 6)}

A AFPT dos indivíduos melanodermas brasileiros, assim como a AFPS, apresentou dimorfismo entre os gêneros e maior desenvolvimento vertical da face posterior para o masculino, confirmando os achados de Águila e Águila ${ }^{1}$, que encontraram

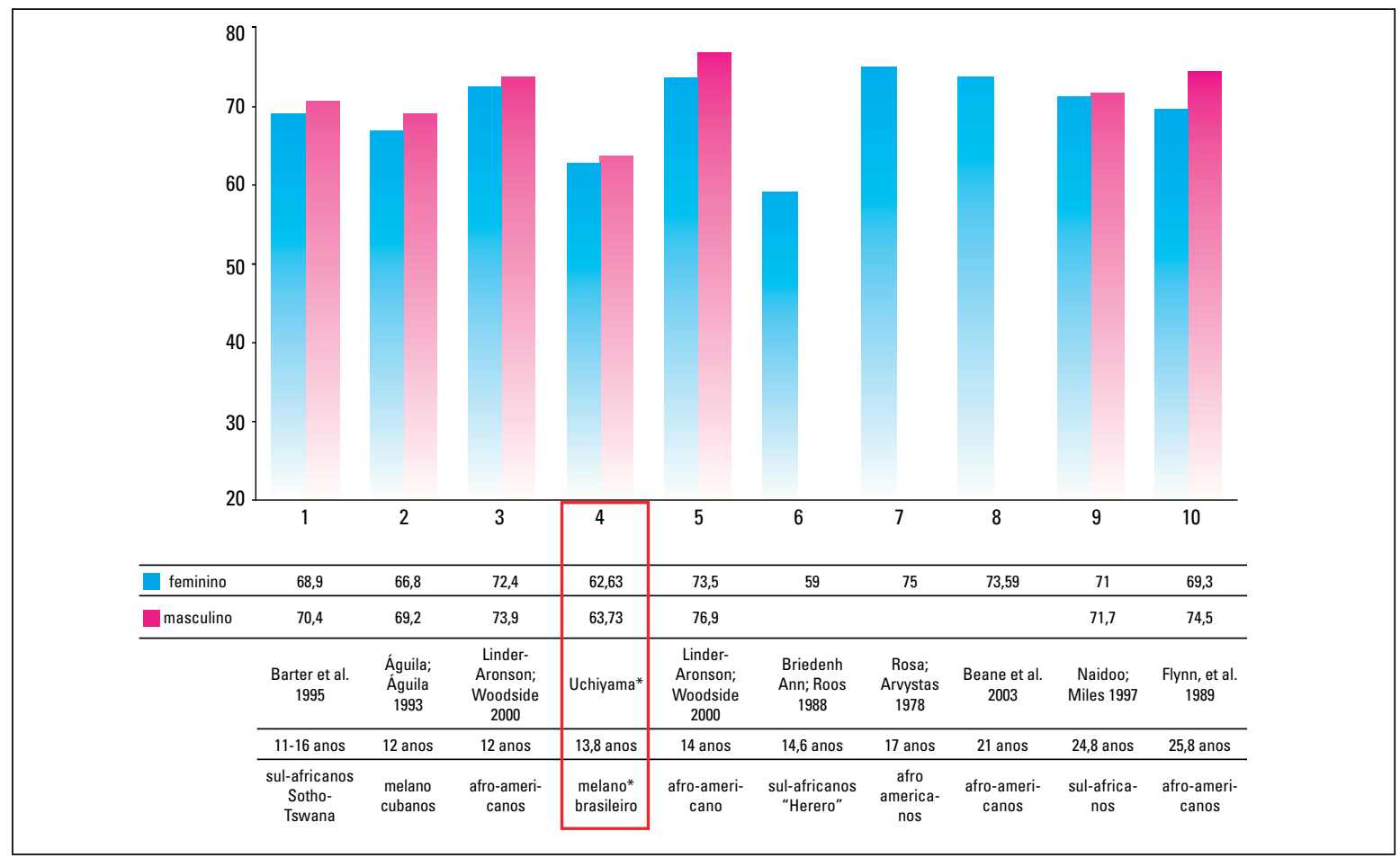

GRÁFICO 3 - Valores de AFAI da amostra de melanodermas: brasileiros x áreas geográficas distintas. 


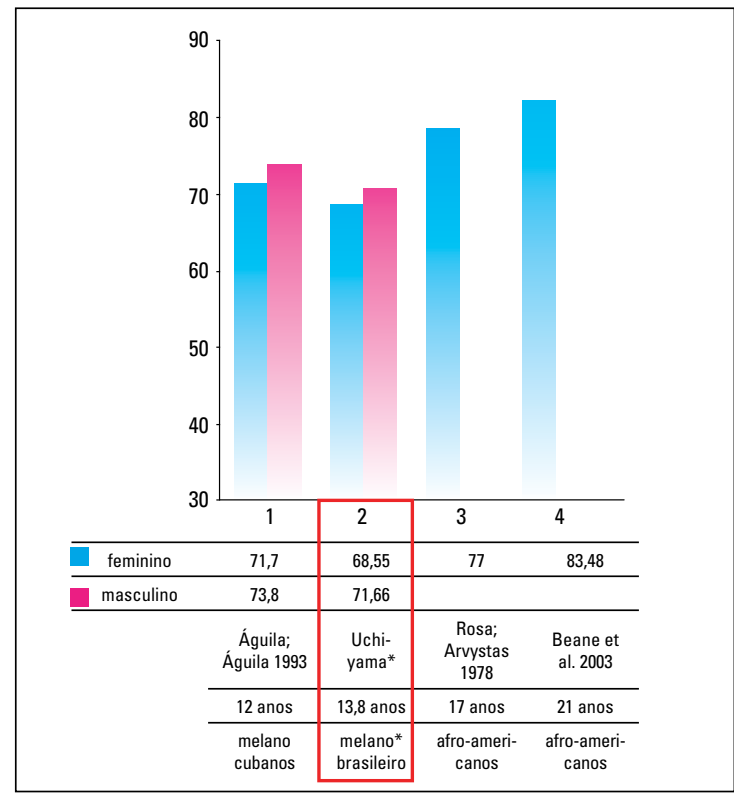

GRÁFICO 4 - Valores de AFPT da amostra de melanodermas: brasileiros $\mathrm{x}$ áreas geográficas distintas.

*Dimorfismo entre gêneros (pesquisa de UCHIYAMA).

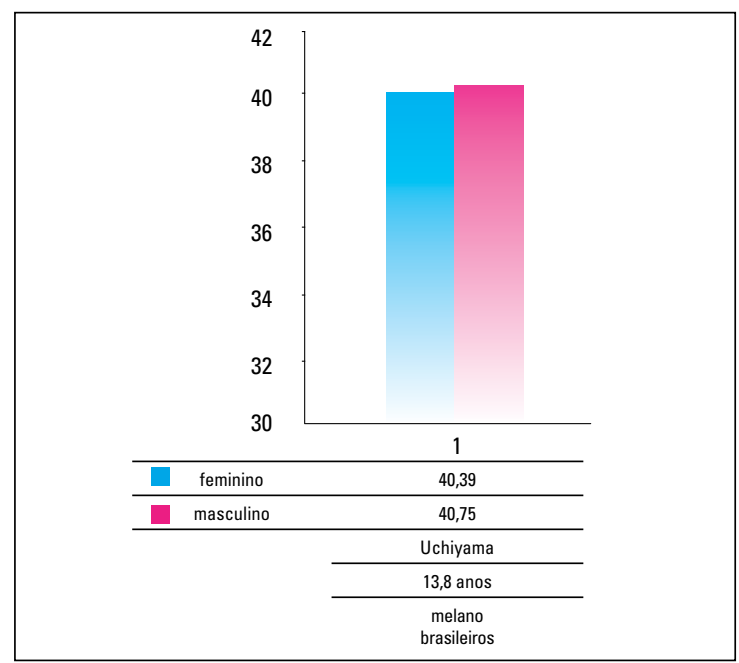

GRÁFICO 6 - Valores de AFPI da amostra de melanodermas brasileiros.

maior crescimento da dimensão vertical posterior e anterior da face no gênero masculino, tornando-se proporcionalmente maior que as faces femininas.

Estudos sobre o crescimento vertical da face com oclusão normal afirmam que a altura facial posterior desenvolve-se mais que a anterior, o que não foi observado no presente trabalho, que apresentou valores da AFAT amplamente superiores

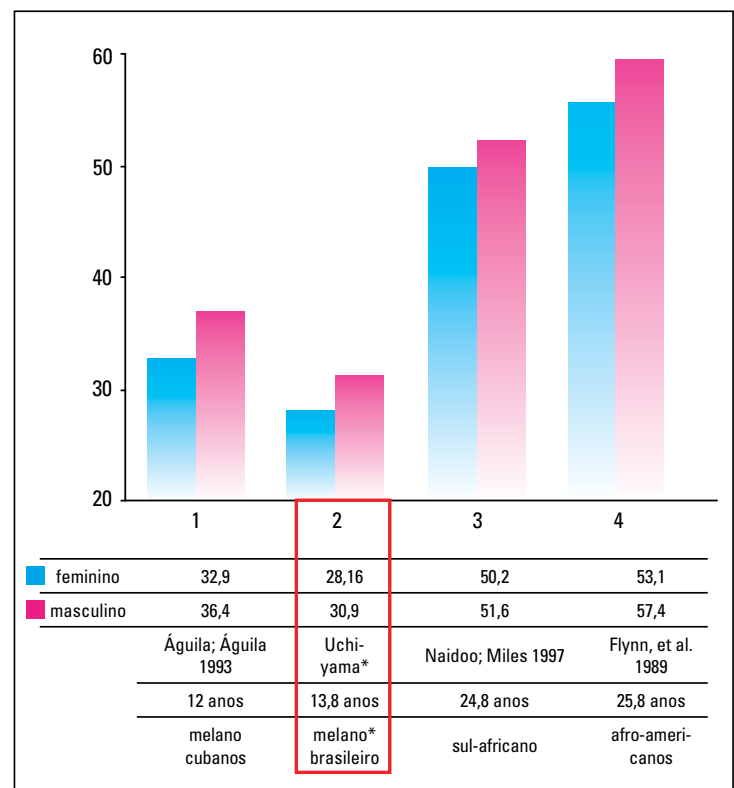

GRÁFICO 5 - Valores de AFPS da amostra de melanodermas: brasileiros $x$ áreas geográficas distintas.

*Dimorfismo entre gêneros (pesquisa de UCHIYAMA).

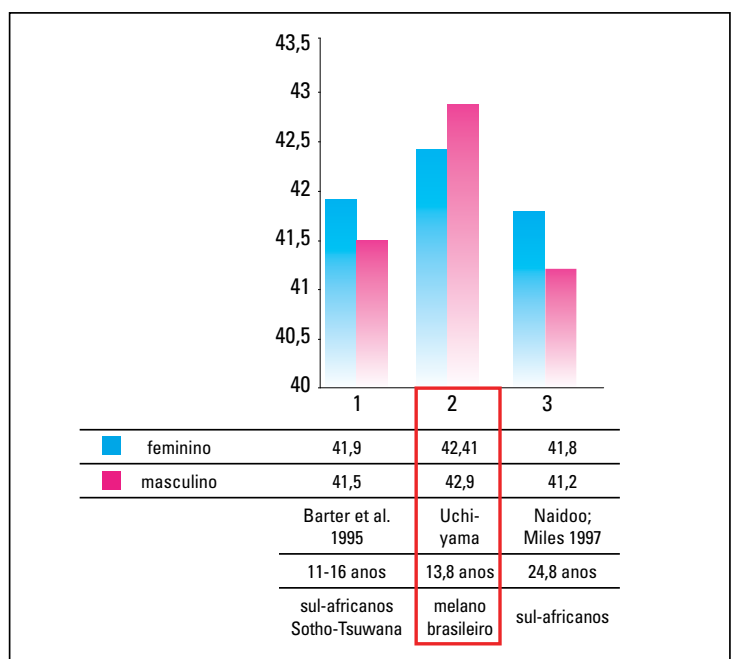

GRÁFICO 7 - Valores de AFAS/AFAT da amostra de melanodermas: brasileiros $x$ áreas geográficas distintas.

ao da AFPT. Isto pode ser explicado pelas diferenças nos padrões de crescimento das amostras e principalmente pela idade. Inicialmente, ocorre maior desenvolvimento da altura facial anterior em jovens de ambos os gêneros, descrito na literatura por Bishara ${ }^{8,9}$.

Beane et $\mathrm{al}^{7}{ }^{7}$, ao estudarem dois grupos de melanodermas com e sem mordida aberta anterior 
concluíram que a AFP é fortemente correlacionada à idade do paciente e após a compatibilidade das idades, a diferença entre os grupos não foi significante.

Os resultados da AFPT de Beane et al. '; Águila, Águila ${ }^{1}$ e Rosa ${ }^{40}$ e da AFPS de Flynn ${ }^{20}$, Naidoo e Miles $^{36}$ foram também superiores aos valores encontrados para o grupo melanodermas brasileiros. Deve-se salientar, porém, que pontos de referências diferentes foram utilizados por Flynn ${ }^{20}$, Naidoo e Miles $^{36}$ para determinar a AFPS.

A AFPI do grupo estudado não apresentou diferença estatística significante, indicando ausência de dimorfismo entre os gêneros. Naidoo e Miles ${ }^{37}$ encontraram uma altura do ramo (Ar-Go) menor no grupo sul-africano, especialmente do gênero masculino, corroborando os resultados de Barter ${ }^{5}$.

\section{Proporções entre as alturas faciais (AFAS/ AFAT, AFAI/AFAT; AFPS/AFPT; AFPI/AFPT) (Gráf. 7-10)}

Tão importante quanto observar as alterações ocorridas nas grandezas cefalométricas é considerar as proporções existentes entre as várias dimen-

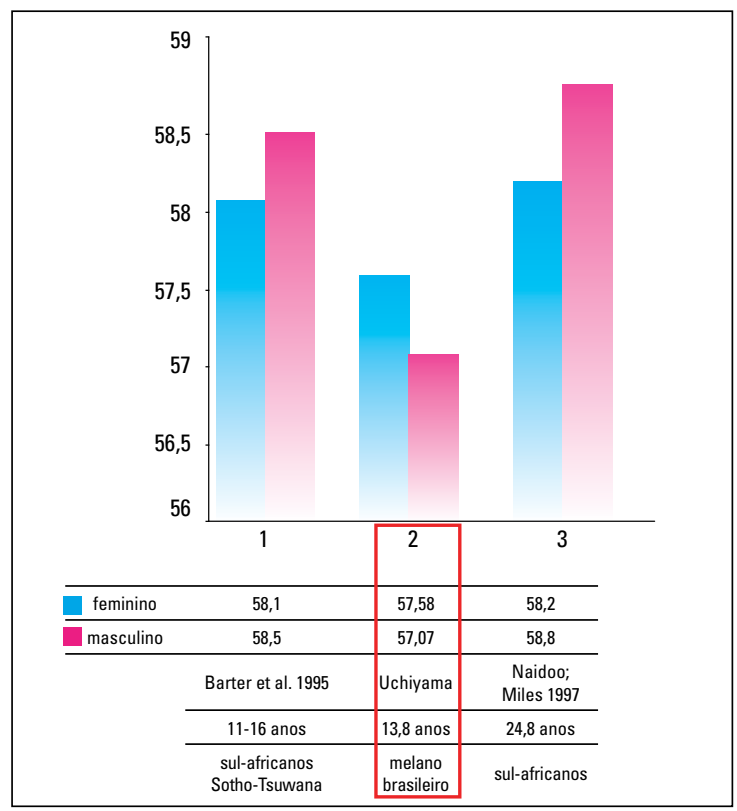

GRÁFICO 8 - Valores de AFAI/AFAT da amostra de melanodermas: brasileiros $\mathrm{x}$ áreas geográficas distintas. sões da face.

A proporção entre a AFAS e AFAT mostrou ser constante nas diferentes etnias, não apresentando dimorfismo entre os gêneros ${ }^{51}$. A ausência de dimorfismo foi também observada na presente amostra para esta grandeza, assim como para a proporção AFAI/AFAT. Foram encontrados maiores valores para a AFAI em relação à AFAS em toda a literatura para melanodermas, assim como na amostra do presente trabalho, os valores mais significativos entre estas duas grandezas foram alcançados por AFAI/AFAT, confirmando os resultados de Naidoo, Miles ${ }^{36}$; Barter ${ }^{5}$; Briedenhann e Roos $^{12}$, os quais se aproximaram significativamente dos resultados para as referidas proporções anteriores na amostra de melanodermas brasileiros.

Os valores encontrados pelo presente estudo para AFPS/AFPT assim como para AFPI/AFPT apresentaram dimorfismo entre os gêneros, divergindo dos relatos de Bishara ${ }^{8,9}$. Uma maior proporção AFPS/AFPT foi encontrada para o gênero masculino e o gênero feminino apresentou valor superior de AFPI. A AFPI/AFPT apresentou maiores valores que a proporção AFPS/AFPT.

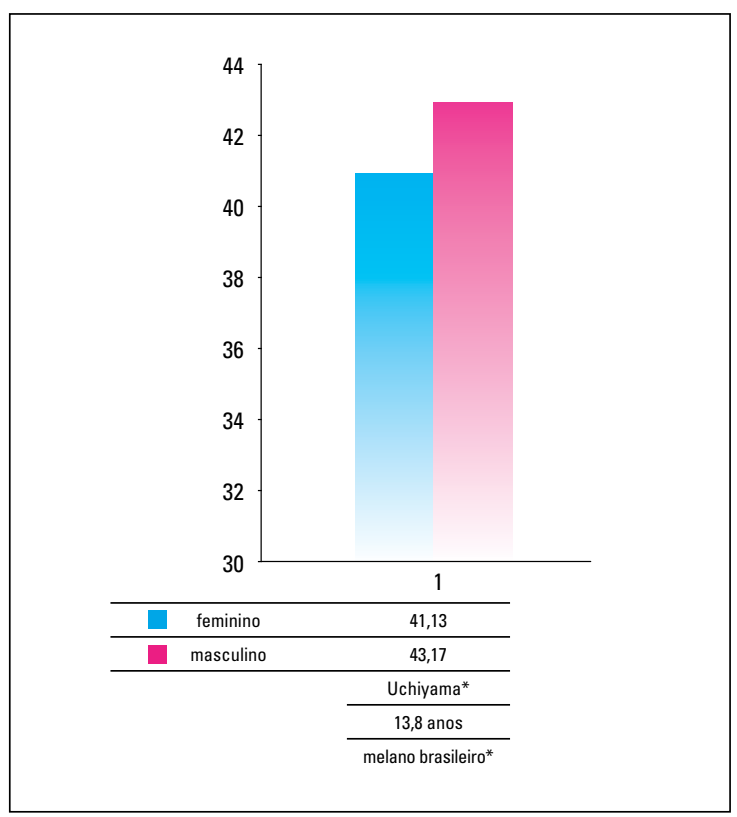

GRÁFICO 9 - Valores de AFPS/AFPT da amostra de melanodermas brasileiros. *Dimorfismo entre gêneros (pesquisa de UCHIYAMA). 


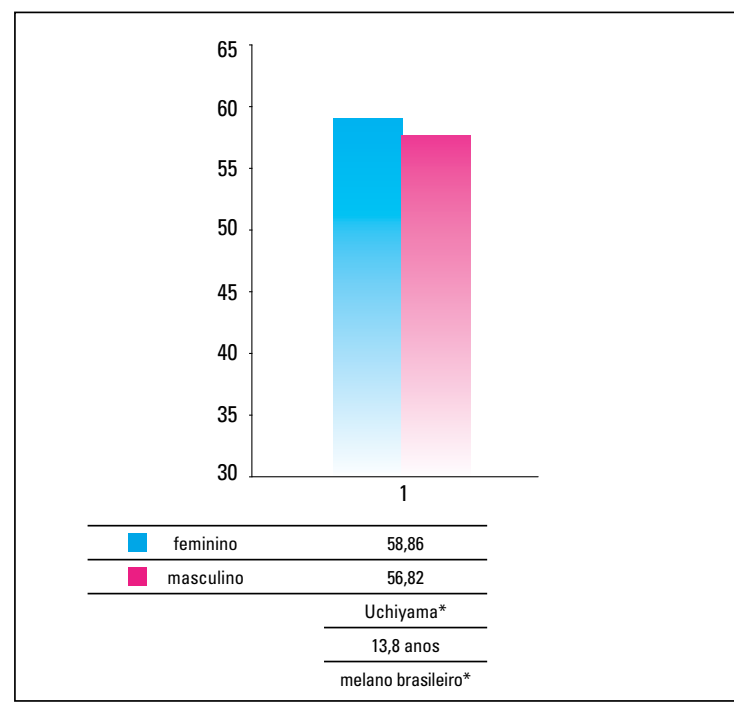

GRÁFICO 10 - Valores de AFPI/AFPT da amostra de melanodermas brasileiros. *Dimorfismo entre gêneros (pesquisa de UCHIYAMA).

\section{IAF (Gráf. 13)}

O índice da altura facial, descrito por Horn ${ }^{23}$, é definido pela proporção entre a altura facial posterior (AFP) (Gráf. 12) e a altura facial anterior (AFA) (Gráf. 11). Este índice indica o sentido da rotação mandibular durante o tratamento ortodôntico e permite o conhecimento da relação dinâmica entre AFA e AFP, com o objetivo de maior controle sobre a altura facial anterior e melhora da altura facial posterior. Esse controle é ainda mais importante no que se refere aos indivíduos melanodermas, devido aos significantes valores de AFAI apresentados na literatura ${ }^{1,3,5,7,12,20,30,36,40}$.

No grupo de melanodermas brasileiros, os valores encontrados não apresentaram diferença estatística significante, indicando ausência de dimorfismo entre os gêneros. $\mathrm{O}$ valor médio da presente amostra foi superior ao valor apresentado de Briedenhann e Roos ${ }^{12}$ para os sul-africanos de idioma "herero".

\section{CONSIDERAÇÕES CLÍNICAS}

É incontestável a dificuldade em se descrever as displasias esqueléticas verticais mediante somente a classificação ântero-posterior convencio-

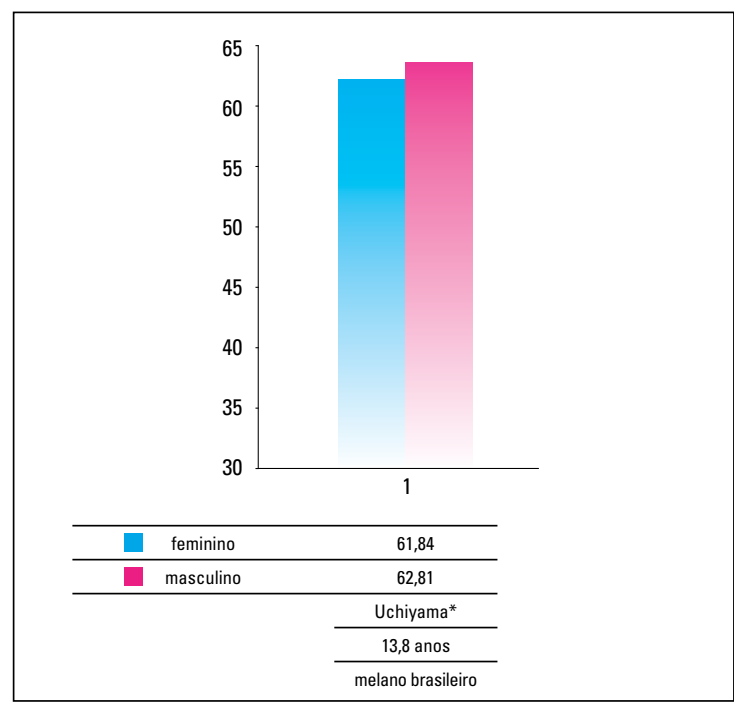

GRÁFICO 11 - Valores de AFI da amostra de melanodermas brasileiros.

nal (Classe I, II, III). A importância do controle da mecânica estabelecida no tratamento ortodôntico nos sentidos ântero-posterior e vertical define o sucesso do tratamento ${ }^{31}$. O desenvolvimento e o crescimento facial são de interesse do clínico, visto que a quantidade e direção do crescimento irão alterar de forma significativa a necessidade da terapia ortodôntica e a mecânica que será aplicada ${ }^{43}$. As controvérsias em diversos estudos apresentam que os efeitos da ação terapêutica do tratamento ortodôntico atuam principalmente nos componentes dentoalveolares, seguido dos componentes do complexo facial e influenciando o crescimento, seja em quantidade ou direção. Com base nesta afirmativa, a literatura abordou inúmeros estudos que correlacionaram o aumento da dimensão vertical, associado aos diversos componentes, atuando de forma individual ou em comum, com o crescimento craniofacial.

A literatura é unânime em ressaltar uma maior contribuição da AFAI em relação à AFAS na altura facial total de indivíduos negros de diferentes regiões geográficas $1,3,5,7,20,30$. O aumento da AFAI em indivíduos melanodermas é descrito na literatura $^{5}$ como um mecanismo compensatório que re- 


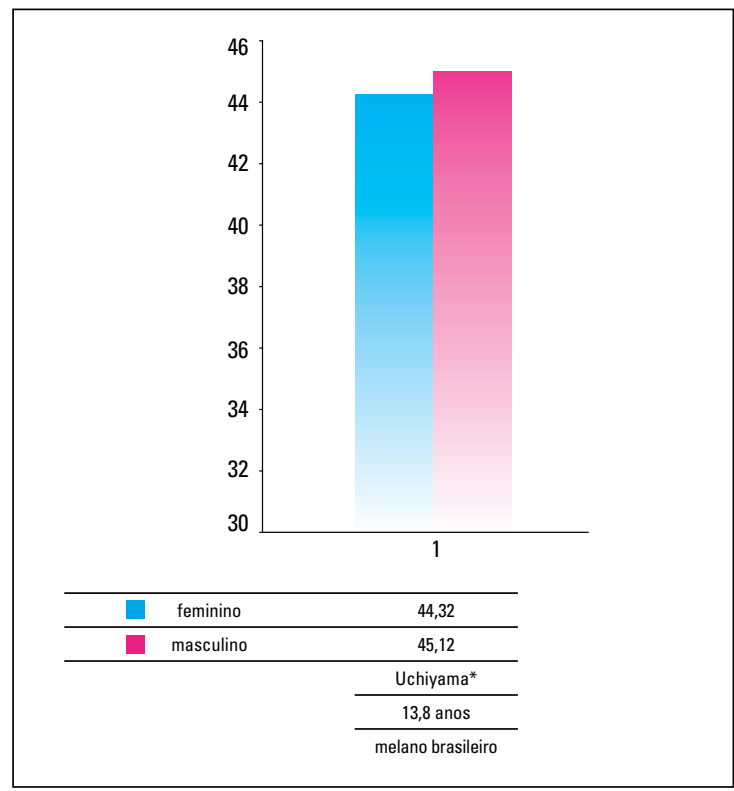

GRÁFICO 12 - Valores de AFP da amostra de melanodermas brasileiros.

duz a possibilidade da ocorrência de uma relação de má oclusão de Classe III, que seria ocasionado pelo aumento do tamanho do corpo da mandíbula presente nestes indivíduos 5 .

A relação entre a rotação dos maxilares e as alterações nas proporções faciais foram investigadas por vários autores. Estes autores sugeriram que deve existir harmonia na quantidade, direção de crescimento e grau de rotação entre a maxila e a mandíbula, se as proporções faciais constantes forem mantidas. $\mathrm{O}$ crescimento vertical extremo ou a rotação horária da maxila necessita de uma quantidade compensatória de rotação mandibular para manter a relação vertical e ântero-posterior. Isto pode ser conseguido somente com uma adequada quantidade de crescimento vertical do côndilo ${ }^{10,50}$.

Além disso, Beane et al. ${ }^{7}$ associaram a mordida aberta com o aumento da AFAI nos melanodermas. Esses dados devem ser considerados clinicamente, no tratamento destes indivíduos. Resumidamente, os autores concluíram que: os indivíduos melanodermas com mordida aberta se diferem daqueles que não a apresentam na extensão do padrão de desenvolvimento vertical na região anterior da

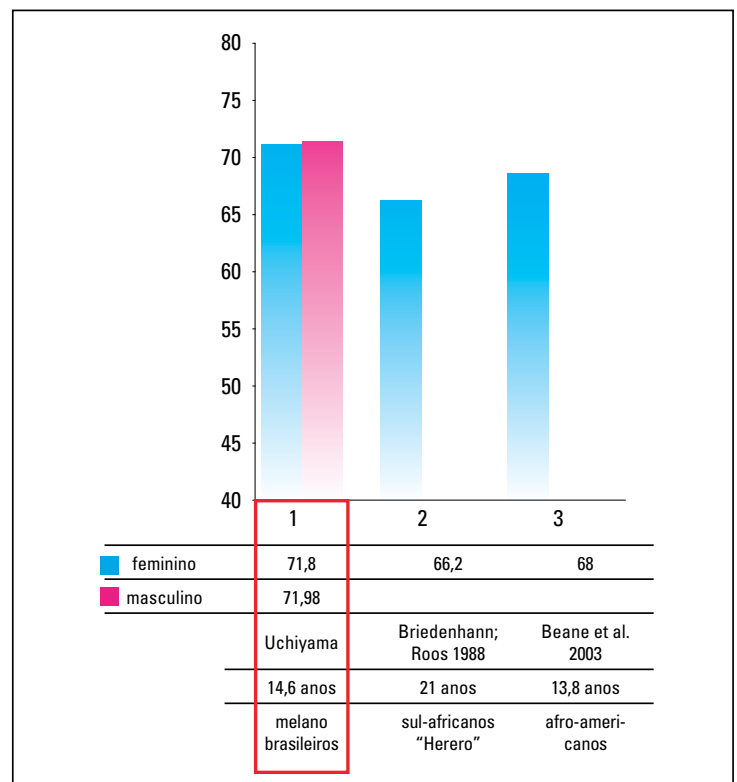

GRÁFICO 13 - Valores de IAF da amostra de melanodermas: brasileiros $\mathrm{x}$ áreas geográficas distintas.

face e rotação mandibular e que uma inclinação dentoalveolar protrusiva seria um componente significativo desta má oclusão.

A correlação entre as alturas faciais ânteroinferior e superior, com a posição vertical dentoalveolar destaca-se como um fator relevante no planejamento ortodôntico ${ }^{28}$. Um exemplo seria a aplicação de mecânica com forças extrusivas dentoalveolares para melhorar e interferir no componente vertical, em indivíduos com a altura facial ântero-inferior diminuída ${ }^{28}$. Os dentes superiores apresentariam uma alta correlação com as alturas faciais, tanto superior como inferior ${ }^{28}$.

A modificação da posição dentária afetará a postura labial, devido à íntima relação que os lábios mantêm com a posição das estruturas alveolares e dentárias ${ }^{45}$. Desta forma, Carter $^{13}$ indicou as extrações dentárias apenas para a dissolução de apinhamento, pois considera o prognóstico duvidoso no caso das extrações que objetivam puramente de retroposição dos lábios, prevendo a possibilidade de abertura dos espaços das extrações, comprometendo a estabilidade pós-tratamento.

As possibilidades de tratamento para os pacien- 
tes verticalmente equilibrados são mais numerosas, incluindo inclusive abordagens ortopédicas, as quais, se combinadas ao tratamento ortodôntico sem extrações, podem resultar em características oclusais e estéticas satisfatórias. Neste aspecto, é de fundamental importância que se discuta e leve em consideração os interesses do paciente quanto ao resultado estético final esperado, já que as características faciais são influenciadas pelo tratamento ortodôntico.

Yehezkel ${ }^{52}$ relatou uma preferência por um perfil mais retilíneo dos indivíduos do gênero feminino afro-americanos do século XX. Entretanto é importante ressaltar que o conceito de estética é extremamente subjetivo e está condicionado às influências sócio-culturais.

Um diferencial positivo para a presente amostra é a questão funcional, evidenciada pela presença de selamento labial passivo e conseqüente rotina fisiológica, o que torna as circunstâncias mais favoráveis. Porém, cabe ao ortodontista, ao se deparar com este tipo de paciente na clínica, avaliar a oclusão (de maneira estática e dinâmica), a face, a telerradiografia, investigar as expectativas do paciente, seu conceito em relação à auto-imagem, preservando suas características raciais próprias, e a melhor opção de tratamento, a fim de favorecer o prognóstico.

Considera-se ainda a necessidade de estudos das análises cefalométricas, que avaliam os grupos de mestiços, pois para eles quais os parâmetros que devem ser aplicados?

\section{CONCLUSÕES}

Com base na metodologia e nos resultados apresentados torna-se lícito afirmar que para os melanodermas brasileiros:

- O presente trabalho quantificou valores médios para as alturas e proporções faciais tanto anteriores como posteriores, para ambos os gêneros, sem perder de vista a incontestável variabilidade individual e étnica. Ressaltando que esta variabilidade estaria relacionada à morfologia e padrão facial da presente amostra. O conhecimento das diferenças cefalométricas tem como conseqüência um melhor entendimento da patogenia, diagnóstico e tratamento das discrepâncias faciais verticais $^{42}$, já que a leitura da face e dos arcos dentários está subordinada ao entendimento cefalométrico normativo.

- Ocorreu a presença de dimorfismo entre os gêneros, nas seguintes medidas: alturas faciais anterior e posterior total e superior (AFAT; AFAS; AFPT; AFPS) e as proporções faciais superior e inferior, com a altura posterior total (AFPS/AFPT; AFPI/AFPT). Apresentando um maior desenvolvimento vertical anterior da face no gênero masculino. Uma maior proporção AFPS/AFPT foi encontrada para o gênero masculino e o gênero feminino apresentou valor superior de AFPI. 


\title{
Cephalometric study of anterior and posterior facial height in black young Brazilians with "normal occlusion"
}

\begin{abstract}
Aim: in order to present specific cephalometric norms to black young Brazilians, this study aimed to achieve the mean normal values for some vertical skeletal cephalometric variables (anterior and posterior facial heights) and to verify the presence of dimorphism between genders. Methods: the sample comprised 56 lateral cephalograms, 28 male subjects, at a mean age of 13.93 years (range 12.08 to 15.75 years), and 28 females, at a mean age of 13.79 years (range 12.58 to 15.67 years), obtained from an untreated sample of black young Brazilians, presenting "normal occlusion", from the files of Orthodontic Department at Bauru Dental School - University of São Paulo. The cephalometric measurements were based on analyses of Wylie, Johnson; Siriwat, Jarabak; Gebeck, Merrifield, Horn. The comparison between genders was performed by independent $t$ tests. Results: based on this study' results, it was verified that black young Brazilians present specific norm values to vertical skeletal cephalometric variables. It was observed the presence of dimorphism in the variables total and upper anterior facial height and total and upper posterior facial height (TAFH; UAFH; TPFH; UPFH), and in the ratios of upper and lower posterior with the total posterior facial height (UPFH/TPFH; LPFH/TPFH). It was demonstrated a larger vertical facial development in male subjects. A greater UPFH/TPFH ratio was found in males subjects and the females presented highest values of LPFH. Conclusion: the cephalometric norms guide the professionals to respect the morphology and the facial pattern considering individual factors, as racial miscegenation and geographic origin.
\end{abstract}

Key words: Orthodontic diagnosis. Ethnic groups. Vertical dimension. Cephalometrics.

\section{REFERÊNCIAS}

1. ÁGUILA, F. J.; ÁGUILA, G. Atlas de cefalometria. São Paulo: Pancast, 1993

2. ALCALDE, R. E. et al. Cephalometric norms in Japanese adults. J Oral Maxillofac Surg, Philadelphia, v. 56, p.129-134, 1998.

3. BACON, W.; GIRARDIN, P.; TURLOT, J. C. A comparison of cephalometric norms for the African Bantu and a Caucasoid population. Eur J Orthod, Oxford, v. 5, p. 233-240, 1983.

4. BAILEY, K. L.; TAYLOR, W. H. Mesh diagram cephalometric nor$\mathrm{ms}$ for Americans of African descendent. Am J Orthod Dentofacial Orthop, St. Louis, v. 114, p. 218-223, 1998.

5. BARTER, M. A. et al. Cephalometric analysis of a Sotho-Tswana group. J Dent Assoc S Afr, Cape Town, v. 50, p. 539-544, 1995.

6. BAUMRIND, S.; FRANTZ, R. C. The reliability of head film measurements - part 2. Conventional angular and linear measures. Am J Orthod, St. Louis, v. 60, p. 505, 1971.

7. BEANE, R. A. et al. A cephalometric comparison of black openbite subjects and black normals. Angle Orthod, Appleton, v. 73, no. 3, p. 294-300, 2003.

8. BISHARA, S. E. et al. Changes in the dental arches and dentition between 25 and 45 years of age. Angle Orthod, Appleton, v. 66, no. 6, p. 416-422, Aug. 1996

9. BISHARA, S. E.; TREDER, J. E.; JAKOBSEN, J. R. Facial and dental changes in adulthood. Am J Orthod Dentofacial Orthop St. Louis, v. 106, p.175-186, Aug. 1994.

10. BJÖRK, A. Prediction of mandibular growth rotation. Am J Orthod, St. Louis, v. 55, no. 6, p. 585-599, June 1969

11. BJÖRK, A.; SKIELLER, V. Facial development and tooth eruption: an implant study at the age of puberty. Am J Orthod, St. Louis, v. 62, no. 4, p. 339-383, Oct. 1972.

12. BRIEDENHANN, S. J.; ROOS, E. C. A cephalometric appraisal of the Herero-speaking negro male. J Dent Assoc S Afr, Cape Town, v. 43, p. 569-575, 1988.
13. CARTER, N. E.; SLATTERY, D. A. Bimaxillary proclination in patients of Afro-Caribbean origin. Br J Orthod, Oxford, v. 15, p. 175-184, 1988

14. CONNOR, A. M.; MOSHIRI, F. Orthognathic surgery norms for American black patients. Am J Orthod, St. Louis, v. 87, no. 2, p. 119-134, Feb. 1985

15. COOK, M. S.; WEI, S. H. I. A comparative study of southern Chinese and British Caucasian cephalometric standards. Angle Orthod, Appleton, v. 59, p. 131-138, 1989.

16. DAHLBERG, G. Statistical methods for medical and biological students. New York: Interscience, 1940.

17. DRUMMOND, R. A determination of cephalometric norms of the Negro race. Am J Orthod, St. Louis, v. 54, p. 670-682, 1968.

18. ENCICLOPEDIA Delta Larousse. Rio de Janeiro: Delta, 1965.

19. FIELDS, H. W. et al. Facial pattern differences in long-faced children and adults. Am J Orthod, St. Louis, v. 85, no. 3, p. 217-223, Mar. 1984.

20. FLYNN, T. R.; AMBROGIO, R. I.; ZEICHNER, S. J. Cephalometric norms of orthognathic surgery in black American adults. J Oral Maxillofac Surg, Philadelphia, v. 47, no. 1, p. 30, Jan. 1989

21. GEBECK, T. R.; MERRIFIELD, L. L. Analysis - concepts and values. Part I. J Charles H Tweed Int Found, Menlo Park, v. 17, p. 19-48, Apr. 1989.

22. HARRIS, J. E. et al. Age and race as factors in craniofacial growth and development. J Dent Res, Chicago, v. 56, no. 3, p. 266-274, Mar. 1977.

23. HORN, A. J. Facial height index. Am J Orthod Dentofacial Orthop, St. Louis, v. 102, no. 2, p. 180-186, Aug. 1992

24. HOUSTON, W. J. B. The analysis of errors in orthodontic measurements. Am J Orthod, St. Louis, v. 83, no. 5, p. 382-390, May 1983.

25. HWANG, H.; KIM, W.; McNAMARA JR., J. A. Ethnic differences in the soft tissue profile of Korean and European-American adults with normal occlusions and well-balanced faces. Angle Orthod, Appleton, v. 72, no. 1, p. 72-80, 2002.

26. INTERLANDI, S. O cefalograma padrão do curso de pós-graduação de Ortodontia da Faculdade de Odontologia da USP. Rev Faculd Odontol Bauru, Bauru, v. 6, n. 1, p. 63-74, jan./mar. 1968. 
27. JACOBSON, A. The craniofacial skeleton of the South African Negro. Am J Orthod, St. Louis, v. 73, p. 681-691, 1978.

28. JANSON, G. R. P.; METAXAS, A.; WOODSIDE, D. G. Variation in maxillary and mandibular molar and incisor vertical dimension in 12-year-old subjects with excess, normal and short lower anterior face height. Am J Orthod Dentofacial Orthop, St. Louis, v. 106, no. 4, p. 409-418, Oct. 1994.

29. KROGMAN, W. M.; SASSOUNI, V. A syllabus in roentgenographic cephalometric. Philadelphia: College Offset, 1957.

30. LINDER-ARONSON, S.; WOODSIDE, D. G. Excess face height malocclusion: etiology, diagnosis and treatment. Chicago: Quintessence, 2000.

31. MARUO, H. Tratamento de uma Classe II divisão 1 severa em paciente adulto: sucesso ou insucesso? Rev Dental Press Ortodon Ortop Facial, Maringá, v. 6, n. 3, p. 65-72, maio/jun. 2001.

32. MERRIFIELD, L. L. Analysis: concepts and values. Part II. J Charles H Tweed Int Found, Menlo Park, v. 17, p. 49-64, Apr. 1989.

33. MIYAJIMA, K. et al. Craniofacial structure of Japanese and European-American adults with normal occlusions and well-balanced faces. Am J Orthod Dentofacial Orthop, St. Louis, v. 110, p. 431-438, 1996.

34. MIYASHITA, K. Contemporary cephalometric radiography Tokyo: Quintessence, 1996.

35. NAHOUM, H. I. Vertical proportions and the palatal plane in anterior open-bite. Am J Orthod, St. Louis, v. 59, p. 273-282, 1971.

36. NAIDOO, L. C. D.; MILES, L. P. An evaluation of the mean cephalometric values for orthognathic surgery for black South Africa adults. Part I: Hard tissue. J Dent Assoc S Afr, Cape Town, v. 52 , p. $495-502,1997$.

37. NAIDOO, L. C. D.; MILES, L. P. An evaluation of the mean cephalometric values for orthognathic surgery for black South Africa adults. Part II: Soft tissue. J Dent Assoc S Afr, Cape Town, v. 52, p. 545-550, Sept. 1997.

38. ORTIAL, J. P. Vertical dimensional and therapeutic choices. Am J Orthod Dentofacial Orthop, St. Louis, v. 108, no. 4 p. 432-441, Oct. 1995

39. RICHARDSON, E. R. Racial differences in dimensional traits of the human face. Angle Orthod, Appleton, v. 50, no. 4, p. 301-309, Oct. 1980
40. ROSA, R. A.; ARVYSTAS, M. G. An epidemiologic survey of malocclusions among American Negroes and American Hispanics. Am J Orthod, St. Louis, v. 3, no. 3, p. 258-273, 1978.

41. SASSOUNI, V.; NANDA, S. Analysis of dentofacial vertical proportions. Am J Orthod, St. Louis, v. 50, no. 11, p. 801-823, Nov. 1964.

42. SCHENDEL, S. A. The long face syndrome: vertical maxillary excess. Am J Orthod, St. Louis, v. 70, no. 4, p. 398-408, Oct. 1976.

43. SINCLAIR, P. M.; LITTLE, R. M. Dentofacial maturation of untreated normals. Am J Orthod, St. Louis, v. 88, no. 2, p.146-156, Aug. 1985.

44. SIRIWAT, P. P.; JARABAK, J. R. Malocclusion and facial morphology: is there a relationship? An epidemiologic study. Angle Orthod, Appleton, v. 55, no. 2, p.127-138, Apr. 1985

45. SUBTELNY, J. D.; SAKUDA, M. Open bite: diagnosis and treatment. Am J Orthod, St. Louis, v. 50, p. 337-358, 1964.

46. TAKAHASHI, R. Determinação cefalométrica das alturas faciais anterior e posterior, em jovens brasileiros, descendentes de xantodermas e leucodermas, com oclusão normal 2002. 182 f. Tese (Doutorado)-Faculdade de Odontologia de Bauru, Universidade de São Paulo, São Paulo, 2002.

47. VAN DER BEEK, M. C. J.; HOEKSMA, J. B.; ANDERSEN, P. Vertical facial growth: a longitudinal study from 7 to 14 years of age. Eur J Orthod, London, v. 13, no. 3, p. 202-208, May 1991.

48. VION, P. E. Anatomia cefalométrica. São Paulo: Ed. Santos, 1994

49. WOODSIDE, D. G. The channelization of upper and lower anterior face heights compared to population standard in males between ages 6 to 20 years. Eur J Orthod, London, v. 1, no. 1 p. 25-40, 1979.

50. WYLIE, W. L. The relationship between ramous height, dental height and overbite. Am J Orthod, St. Louis, v. 32, p. 57-67, 1947

51. WYLIE, W. L.; JOHNSON, E. L. Rapid evaluation of facial dysplasia in the vertical plane. Angle Orthod, Appleton, v. 22, no. 3, p. 165-182, July 1952

52. YEHEZKEL, S.; TURLEY, P. K. Changes in the African American female profile as depicted in fashion magazines during the 20th century. Am J Orthod Dentofacial Orthop, St. Louis, v. 125, no. 4, p. 407-417, Apr. 2004

\section{Endereço para correspondência}

Lívia Maria Andrade de Freitas Uchiyama

Rua Al. Octávio Pinheiro Brizolla, 9-75

CEP: 17.012-901 - Bauru/SP

E-mail: livifret@yahoo.com.br 